\title{
Investigation of body mass index, insulin resistance and diabetes in patients with hirsutism
}

\author{
Besa Gacaferri Lumezi, Violeta Lokaj Berisha
}

Department of Physiology and Immunology, Medical Faculty, University of Prishtina, Prishtina, Kosovo

Adv Dermatol Allergol 2021; XXXVIII (6): 1006-1010

DOI: https://doi.org/10.5114/ada.2020.98132

\begin{abstract}
Introduction: Obese woman with hirsutism have increased risk for developing insulin resistance and diabetes mellitus.

Aim: To evaluate patients with hirsutism, report the hormone levels, body mass index (BMI), insulin resistance and diabetes in our study population and compare our results with those of similar research conducted in other countries.

Material and methods: Hormones were measured with radioimmunoassay/immunoradiometric assay methods. Oral glucose tolerance test was done only in a selected group of women (with positive anamnesis for diabetes, women with polycystic ovary syndrome (PCOS) and overweight/obese women). The level of blood glucose was measured after drinking the liquid containing 75 g glucose. Blood was taken to measure glucose, insulin and C-peptide levels after $30 \mathrm{~min}, 60 \mathrm{~min}$ and $3 \mathrm{~h}$.

Results: Women with PCOS (27.4\%) had higher BMI than women with other causes of hirsutism. Among 135 of the women with hirsutism, 9.6\% were underweight, $60 \%$ were with normal weight, $20.7 \%$ were overweight and $9.6 \%$ were obese. Obesity was more frequent in PCOS and hyperandrogenism groups. Women with hirsutism had higher levels of androstenedione, dehydroepiandrosterone sulfate (DHEAS), total testosterone, free testosterone, lower levels of sex hormone-binding globulin (SHBG). Insulin resistance was present in 20 (14.8\%) women and diabetes in $2(1.4 \%)$ women.

Conclusions: Obesity was associated with increased hirsutism. In our study we found that insulin resistance should be assessed in hirsute women with PCOS regardless of their BMI as insulin resistance was found in hirsute women irrespective of whether they were overweight, obese, of normal weight or underweight. Groups at risk (hirsute, obese, diabetes) should be identified and treated.
\end{abstract}

Key words: body mass index, insulin resistance, diabetes, hirsutism.

\section{Introduction}

Hirsutism is the medical term that refers to presence of excessive terminal hair in androgen-dependent areas of the female body. Especially among young women, hirsutism negatively influences psychological well-being. This is important because hirsutism is among the most frequent medical complaints. Although hirsutism generally reflects hormone imbalances, it can rarely be related to a life-threatening disorder [1].

It affects around $5-10 \%$ of women [2]. The cause is mainly hyperandrogenism, which may be ovarian or adrenal. It may be a part of a rare metabolic syndrome, drug induced, or just idiopathic [3].

Hyperandrogenism is most often caused by the polycystic ovary syndrome. This diagnosis is made when there is otherwise unexplained chronic hyperandrogen- ism and oligo-ovulation or anovulation. Documentation of polycystic ovaries is not necessary for the diagnosis of polycystic ovary syndrome but it is a criterion for it if evidence of anovulation is lacking. About half of the cases are nonclassic - they lack some of the features classically associated with the syndrome (such as menstrual irregularity, polycystic ovaries, or obesity) - and thus the absence of some such features in a hirsute woman does not rule out the diagnosis. Polycystic ovary syndrome is associated with infertility and insulin resistance (manifested as diabetes mellitus or the metabolic syndrome, a variably expressed cluster of findings, including central obesity, hypertension, glucose abnormalities and dyslipidaemia) [4, 5]. Considering the heterogeneity of polycystic ovary syndrome (PCOS), the Rotterdam Consensus has concluded that only obese women with PCOS

\footnotetext{
Address for correspondence: Prof. Ass. Besa Gacaferri Lumezi, Department of Physiology and Immunology, Medical Faculty, University of Prishtina, Bulevardi i deshmoreve p.n. 10000 Prishtina, Kosovo, phone: +38344186036, e-mail: besa_gacaferri@yahoo.com Received: 24.05.2020, accepted: 9.07.2020.
} 
should be screened for the metabolic syndrome. However, hyperinsulinemia and insulin resistance may play a major role in the development of most cases of PCOS as hyperinsulinemia and insulin resistance precede hyperandrogenism [6].

Insulin resistance is worsened by the coexistence of obesity, which is also increased in the PCOS population. More than $40 \%$ of PCOS patients are obese. However, the insulin resistance is disproportionate to the obesity. Obese women with PCOS have greater insulin resistance than weight-matched control subjects or lean PCOS subjects. This is associated with differences in fat distribution. Even in individuals with a non-obese body mass index (BMI), a higher waist-to-hip ratio is seen in those with PCOS compared to those without PCOS. This is supported by the higher proportion of visceral adiposity measured by ultrasound in lean PCOS patients compared to weight-matched control subjects [7].

Up to $27 \%$ of premenopausal women with type 2 diabetes also have PCOS [8].

\section{Aim}

Aim of this study was to evaluate patients with hirsutism, report the hormone levels, BMI, insulin resistance and diabetes in our study population and compare our results with those of similar research conducted in other countries.

\section{Material and methods}

The prospective study included 160 women, 135 with hirsutism and 25 as a control group, aged 14-46 years. We took a detailed history (marital status, infertility, age of onset of hirsutism, duration of hirsutism, progression of hirsutism, age at menarche, menstrual irregularities, deepening of voice, increased muscle mass, androgen alopecia, galactorrhoea, decreased breast size, emotional and mental state, other disorders).

Height, weight and a calculation of BMI was obtained. The normal range of BMI was taken as 18-24.9 $\mathrm{kg} / \mathrm{m}^{2}$. Women with BMI $25-29.9 \mathrm{~kg} / \mathrm{m}^{2}$ were labelled overweight and those having $30 \mathrm{~kg} / \mathrm{m}^{2}$ or more were diagnosed as obese.

Evaluation of hirsutism was done according to Ferriman-Gallwey score, grading 11 androgen sensitive parts (upper lip, chin, chest, hand, arm, thigh, leg, upper part of the back, lower part of the back, upper part of the abdomen, lower part of the abdomen). Grading was done starting with 0 (total absence of terminal hair) up to 4 (extended presence of terminal hair). The value of 8 or above 8 is considered as hirsutism.

Hormones were determined with radioimmunoassay (RIA) and immunoradiometric assay (IRMA) methods. With RIA we measured hormones: estradiol, progesterone, 17-OH-progesterone, total testosterone, free-testos- terone, androstenedione, cortisol, DHEASO4, TSH, T3, T4, and with IRMA method: FSH, LH, prolactin, sex hormonebinding globulin (SHBG) and ACTH. The substances used were produced by Immunotech (USA). Blood was taken in the early follicular phase, between $3^{\text {rd }}$ and $5^{\text {th }}$ day of the menstrual cycle (at 8 a.m. and 6 p.m.). The serum was separated by centrifugation and stored at $-20^{\circ} \mathrm{C}$. Blood for assessing the progesterone level was taken in the middle of the cycle. Oral glucose tolerance test (OGTT) was done in selected women (positive history for diabetes, PCOS and obesity). Blood glucose was measured after patients drank the liquid containing 75 g glucose. We took blood to measure glucose, insulin and C-peptide every $30 \mathrm{~min}$ and $60 \mathrm{~min}$ during a period of $3 \mathrm{~h}$.

\section{Statistical analysis}

The collected data were stored in a special database. Statistical processing was done with statistic packet InStat 3. Numerical data were presented as the index of structure, arithmetic mean, standard deviation, minimal value and maximal value. To test the differences between the groups, $t$-test, Mann-Whitney test, $\chi^{2}$-test, One Way ANOVA, Kruskal Wallis test and Fisher exact test were conducted with a significance level of $p<0.05$.

\section{Results}

We studied the group of 160 women, aged from 14 to 46 years, 130 with hirsutism and 25 as the control group. In the control group, 19 or $76 \%$ of women had normal weight and 6 or $24.0 \%$ were overweight. In the hirsutism group, 81 or $60.0 \%$ had normal weight, 28 or $20.7 \%$ were overweight, 13 or $9.6 \%$ were obese and 13 or $9.6 \%$ were underweight (Table 1).

The mean value of $\mathrm{BMI}$ of the total number of women was $23.6 \pm 4.6 \mathrm{~kg} / \mathrm{m}^{2}$, the range was $10.2-40.1 \mathrm{~kg} / \mathrm{m}^{2}$. The mean BMI of women with hirsutism was $23.7 \pm 4.9 \mathrm{~kg} / \mathrm{m}^{2}$, the range was $10.2-40.1 \mathrm{~kg} / \mathrm{m}^{2}$. The value of $\mathrm{BMI}$ of women in the control group was $23.2 \pm 2.6 \mathrm{~kg} / \mathrm{m}^{2}$, the range was $18.7-28.5 \mathrm{~kg} / \mathrm{m}^{2}$. Using the Mann-Whitney test we did not find any statistical significance between mean value of BMI $(p>0.05)$ (Table 2).

In women with hirsutism, in $18.5 \%$ of cases, the value of insulin in 0 min was increased, in $18.5 \%$ it was decreased and in $63.0 \%$ it was normal. The mean value of insulin in $0 \mathrm{~min}$ was $10.6 \pm 8.4 \mu \mathrm{lU} / \mathrm{ml}$, the range was $2.3-45.4 \mu \mathrm{lU} / \mathrm{ml}$. In $22.2 \%$ of cases, the value of insulin in 30 min was increased, in $33.3 \%$ it was decreased and in $44.4 \%$ it was normal. The mean value of insulin in $30 \mathrm{~min}$ was $60.2 \pm 41.8 \mu \mathrm{lU} / \mathrm{ml}$, the range was $5.9-147.9 \mu \mathrm{lU} / \mathrm{ml}$.

In $37.0 \%$ of cases the value of insulin in 60 min was increased, in $33.3 \%$ it was decreased and in $29.6 \%$ it was normal. The mean value of insulin in 60 min was 52.7 $\pm 40.4 \mu \mathrm{lU} / \mathrm{ml}$, the range was $7.6-190.1 \mu \mathrm{lU} / \mathrm{ml}$. In $25.9 \%$ of cases, the value of insulin in 120 min it was increased, in $29.6 \%$ it was decreased and in $44.4 \%$ it was normal. The 
Table 1. Body mass index (BMI) in the study group of women and the control group

\begin{tabular}{lcccccc}
\hline \multirow{2}{*}{ BMI } & \multicolumn{2}{c}{ Study group } & \multicolumn{2}{c}{ Control group } & \multicolumn{2}{c}{ Total } \\
\cline { 2 - 7 } & $\boldsymbol{N}$ & $\%$ & $\boldsymbol{N}$ & $\%$ & $\boldsymbol{N}$ & $\%$ \\
\hline Underweight & 13 & 9.6 & - & - & 13 & 8.1 \\
\hline Normal & 81 & 60.0 & 19 & 76.0 & 100 & 62.5 \\
\hline Overweight & 28 & 20.7 & 6 & 24.0 & 34 & 21.3 \\
\hline Obese & 13 & 9.6 & - & - & 13 & 8.1 \\
\hline Total & 135 & 100.0 & 25 & 100.0 & 160 & 100.0 \\
\hline
\end{tabular}

Table 2. Parameters of body mass index (BMI) in the study group and the control group

\begin{tabular}{lccc}
\hline Parameter & Study group & Control group & Total \\
\hline$N$ & 135 & 25 & 160 \\
\hline Mean value & 23.7 & 23.2 & 23.6 \\
\hline SD & 4.9 & 2.6 & 4.6 \\
\hline Min. & 10.2 & 18.7 & 10.2 \\
\hline Max. & 40.1 & 28.5 & 40.1 \\
\hline Mann-Whitney test & \multicolumn{4}{c}{$p=0.832$} \\
\hline
\end{tabular}

Table 3. The level of insulin in women with hirsutism (study group) in 0, 30, 60, 120, $180 \mathrm{~min}$

\begin{tabular}{|c|c|c|c|c|c|c|c|c|c|c|}
\hline \multirow[t]{2}{*}{ Insulin $[\mu \mathrm{IU} / \mathrm{ml}]$} & \multicolumn{2}{|c|}{ Insulin $0 \mathrm{~min}$} & \multicolumn{2}{|c|}{ Insulin $30 \mathrm{~min}$} & \multicolumn{2}{|c|}{ Insulin $60 \mathrm{~min}$} & \multicolumn{2}{|c|}{ Insulin $120 \mathrm{~min}$} & \multicolumn{2}{|c|}{ Insulin $180 \mathrm{~min}$} \\
\hline & $N$ & $\%$ & $N$ & $\%$ & $N$ & $\%$ & $N$ & $\%$ & $N$ & $\%$ \\
\hline Decreased & 5 & 18.5 & 9 & 33.3 & 9 & 33.3 & 8 & 29.6 & 5 & 18.5 \\
\hline Normal & 17 & 63.0 & 12 & 44.4 & 8 & 29.6 & 12 & 44.4 & 20 & 74.1 \\
\hline Increased & 5 & 18.5 & 6 & 22.2 & 10 & 37.0 & 7 & 25.9 & 2 & 7.4 \\
\hline Total & 27 & 100.0 & 27 & 100.0 & 27 & 100.0 & 27 & 100.0 & 27 & 100.0 \\
\hline Mean & \multicolumn{2}{|c|}{10.6} & \multicolumn{2}{|c|}{60.2} & \multicolumn{2}{|c|}{52.7} & \multicolumn{2}{|c|}{24.7} & \multicolumn{2}{|c|}{8.9} \\
\hline SD & \multicolumn{2}{|c|}{8.4} & \multicolumn{2}{|c|}{41.8} & \multicolumn{2}{|c|}{40.0} & \multicolumn{2}{|c|}{27.9} & \multicolumn{2}{|c|}{10.2} \\
\hline Min. & \multicolumn{2}{|c|}{2.3} & \multicolumn{2}{|c|}{5.9} & \multicolumn{2}{|c|}{7.6} & \multicolumn{2}{|c|}{2.8} & \multicolumn{2}{|c|}{1.7} \\
\hline Max. & \multicolumn{2}{|c|}{45.4} & \multicolumn{2}{|c|}{147.9} & \multicolumn{2}{|c|}{190.1} & \multicolumn{2}{|c|}{118.9} & \multicolumn{2}{|c|}{45.2} \\
\hline
\end{tabular}

Table 4. Clinical characteristics of the study group

\begin{tabular}{lcccccc}
\hline Parameter & IH $(n=29)$ & HA $(n=43)$ & PCOS $(n=37)$ & NCCAH $(n=26)$ & $P$-value & Significant \\
\hline BMI, mean \pm SD & $23.3 \pm 5.0$ & $23.7 \pm 5.1$ & $24.5 \pm 5.4$ & $23.1 \pm 3.9$ & 0.917 & NS \\
\hline Obesity $(\%)$ & $2(6.9 \%)$ & $6(14.0 \%)$ & $5(13.5 \%)$ & $5(13.5 \%)$ & - & S \\
\hline Insulin $[\mu / \mathrm{l} / \mathrm{ml}]$ & $9.8 \pm 8.3$ & $11.6 \pm 6.5$ & $11.4 \pm 10.5$ & $8.0 \pm 2.1$ & 0.779 & NS \\
\hline C-peptide $[\mathrm{ng} / \mathrm{ml}]$ & $5.2 \pm 2.9$ & $3.1 \pm 1.1$ & $3.0 \pm 2.4$ & $2.0 \pm 0.2$ & 0.096 & NS \\
\hline Testosterone $[\mathrm{nmol} / \mathrm{l}]$ & $2.4 \pm 0.7$ & $4.4 \pm 1.8$ & $3.7 \pm 1.2$ & $4.1 \pm 1.7$ & $<0.0001$ & $\mathrm{~S}$ \\
\hline
\end{tabular}

The differences between the groups, t-test, Mann-Whitney test, $\chi^{2}$-test, One Way ANOVA, Kruskal Wallis test and Fisher exact test were conducted with a significance level of $p<0.05$. IH-idiopathic hirsutism, HA - hyperandrogenism, PCOS-polycystic ovary syndrome, NCCAH - non-classical congenital adrenal hyperplasia.

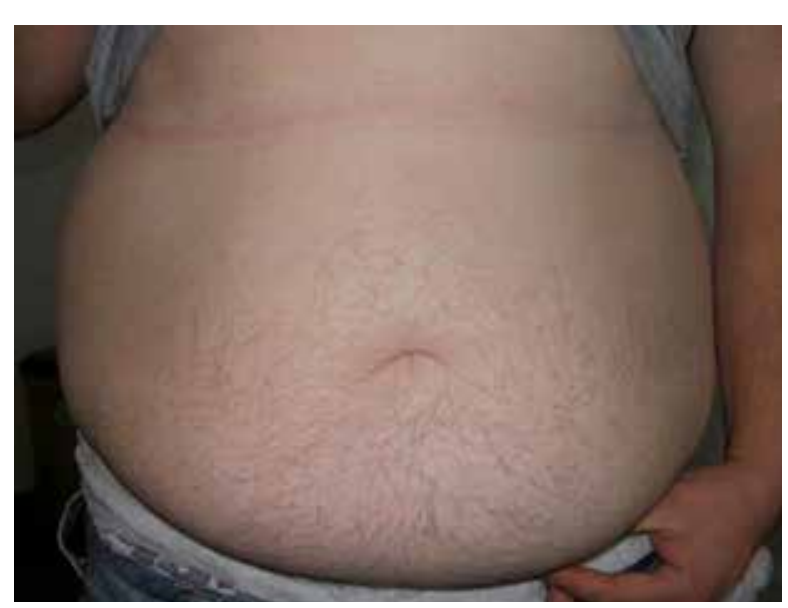

Figure 1. Obese women with hirsutism, PCOS and insulin resistance mean value of insulin in $120 \mathrm{~min}$ was $24.7 \pm 27.9 \mu \mathrm{lU} / \mathrm{ml}$, the range was $2.8-118.9 \mu \mathrm{lU} / \mathrm{ml}$. In $18.5 \%$ of cases, the value of insulin in 180 min was decreased, in $7.4 \%$ it was increased and in $74.1 \%$ it was normal. The mean value of insulin in $180 \mathrm{~min}$ was $8.9 \pm 10.2 \mu \mathrm{lU} / \mathrm{ml}$, the range was 1.7-45.2 $\mu \mathrm{lU} / \mathrm{ml}$ (Table 3).

$\mathrm{BMI}$ was higher in PCOS and hyperandrogenism. There were no significant differences in BMI between aetiology groups/these groups ( $p=0.917$ ). $13.5 \%$ of women with PCOS, $13.5 \%$ with non-classical congenital adrenal hyperplasia (NCCAH) and 14\% of women with idiopathic hyperandrogenism were obese. There were significant differences between these groups ( $p<0.05)$. The insulin level was higher in the hyperandrogenism group and the PCOS group (Figure 1). There were no significant differences in the insulin level between aetiology groups $(p=0.779)$. Testosterone levels were higher in hyperan- 
drogenism and PCOS groups, there were significant differences between aetiology groups ( $p<0.0001$ ) (Table 4).

Women with hirsutism had higher levels of androstenediones (55.6\%), dehydroepiandrosterone sulfate DHEAS (22.2\%), free testosterone (13.3\%), and lower levels of SHBG (41.5\%). Insulin resistance was present in 20 (14.8\%) women and diabetes in 2 (1.4\%) women.

\section{Discussion}

Adipose tissue contains a wide spectrum of enzymes involved in steroid metabolism and contributes up to $50 \%$ of the circulating testosterone in premenopausal women [9].

The increased frequency of hirsutism in obese women may be explained by the production of excess androgens in their adipose tissue. The insulin resistance and increased insulin level of serum is a metabolic consequence of obesity [10-12].

In this study 81 or $60.0 \%$ of women with hirsutism were with normal weight, $9.6 \%$ were underweight; $20.7 \%$ were overweight, and $9.6 \%$ of women with hirsutism were obese. In the control group, 6 women were overweight, and there was no significant difference between the group with hirsutism and the group without hirsutism. So, there are not many similarities with Azziz et al.'s and Farahnaz et al.'s studies $[13,14]$ because in our sample there were less obese women.

Hyperinsulinemia acts as co-gonadotropin with $\mathrm{LH}$ to increase androgen production by ovarian theca cells as the ovary remains sensitive to the action of insulin [15]. Additionally, insulin suppresses hepatic production of SHBG, leading to marked elevation of free or unbound plasma testosterone [16]. But obesity is not always linked to insulin resistance. In our study underweight hirsute women had insulin resistance. Nermeen et al. in their study included 30 patients with idiopathic hirsutism $(\mathrm{IH})$ and normal weight, 16 of them had insulin resistance [17].

In our study, 14\% of women with hyperandrogenism were obese, $13.5 \%$ of women with PCOS were obese. BMI mean values of different aetiology groups tested with Mann-Whitney test, did not show any statistical significance $(p>0.05)$.

Azziz et al. in their study found that more than $58.2 \%$ of women were obese, $1.8 \%$ were underweight, $20.6 \%$ were with normal weight, $19.4 \%$ were overweight, $18.7 \%$ were slightly obese, $17.6 \%$ were moderately obese and $21.9 \%$ were severely obese [13]. Naein et al. included 800 women in their study, of which 400 with hirsutism, and proved that hirsutism was more common among women with high BMI [14]. Guzel et al. in their study found that BMI was higher among hirsute women than among women without hirsutism [18].

OGTT was done in selected women (positive history of diabetes, PCOS and obesity). Women with hyperandrogenism and women with PCOS had higher levels of glucose and insulin, whereas women with NCCAH had lower levels. The highest level of C-peptide was noted rather in women with idiopathic hirsutism. Insulin resistance (as the prediabetic state) was noticed mostly in women with PCOS (of the 37 women with PCOS, insulin resistance was present in 10 or $71.4 \%$ ), the least among women with idiopathic hirsutism. Diabetes mellitus type 1 was present in one woman (0.7\%) and diabetes mellitus type 2 was also present in one woman (0.7\%).

Unluhizarci et al. in their study found that glucose tolerance was present in 10 women (21.7\%), impaired glucose tolerance was present in 8 women (17.4\%) and 2 women (4.3\%) had diabetes mellitus [19], these results are similar with our results. While in a study of Ehrmann et al., 35\% of women with PCOS had glucose intolerance and $10 \%$ of women had diabetes mellitus [20]. Saksena et al. showed that in women with PCOS, $4.7 \%$ had abnormal OGTT [21]. These results are lower than ours. So, women with PCOS have a greater risk of developing insulin resistance and diabetes mellitus type 2 .

\section{Conclusions}

Obesity was associated with increased hirsutism. In our study we found that insulin resistance should be assessed in hirsute women with PCOS regardless of their $\mathrm{BMI}$ as insulin resistance was found in hirsute women irrespective of whether they were overweight, obese, normal weight or underweight. Groups at risk (hirsute, obesity, diabetes) should be identified and treated.

\section{Conflict of interest}

The authors declare no conflict of interest.

\section{References}

1. Escobar-Morreale HF, Carmina E, Dewailly D, et al. Epidemiology, diagnosis and management of hirsutism: a consensus statement by the Androgen Excess and Polycystic Ovary Syndrome Society. Human Reproduction Update 2013; 19: 207.

2. Sanchez LA, Perez M, Azziz R. Laser hair reduction in the hirsute patient: a critical assessment. Hum Reprod Update 2002; 8: 169-81.

3. Sachdeva S. Hirsutism: evaluation and Treatment. Indian J Dermatol 2010; 555: 3-7.

4. Rosenfield RL. Hirsutism. N Engl J Med 2005; 353: 2578-88.

5. Cebeci F, Onsun N, Mert M. Insulin resistance in women with hirsutism. Arch Med Sci 2012; 8: 342-6.

6. Cenk Sayin N, Gucer F, Balkanli-Kaplan P, et al. Insulin resistance and lipid profile in women with polycystic appearing ovaries: implications with regard to polycystic ovary syndrome. Gynecol Endocrinol 2003; 17: 387-96.

7. Sharpless JL. Polycystic ovary syndrome and the metabolic syndrome. Clin Diabetes 2003; 21: 154-61.

8. Peppard HR, Marfori J, Iuorno MJ, et al. Prevalence of polycystic ovary syndrome among premenopausal women with type 2 diabetes. Diabetes Care 2001; 24: 1050-2. 
9. Kershaw EE, Flier JS. Adipose tissue as an endocrine organ. J Clin Endocrinol Metab 2004; 89: 2548-56.

10. Souza FA, Dias R, Fernandes CE, et al. Menstrual irregularity: a possible clinical marker of metabolic dysfunction in women with class III obesity. Gynecol Endocrinol 2010; 26 : 768-72.

11. Svendsen PF, Madsbad S, Nilas L. The insulin resistant phenotype of polycystic ovary syndrome. Fertil Steril 2010; 94: 1052-8.

12. Bhattacharya SM. Insulin resistance and overweight obese women with polycystic ovary syndrome. Gynecol Endocrinol 2010; 26: 344-7.

13. Azziz R, Sanchez LA, Knochenhauer ES, et al. Androgen excess in women: experience with over 1000 consecutive patients. J Clin Endocrinol Metab 2004; 89: 453-62.

14. Naeini FF, Najafian J, Jazeb N. Hirsutism and body mass index in a representative sample of Iranian people. ARYA Atheroscler 2012; 8: 43-54.

15. Barbieri RL, Makris A, Randall RW, et al. Insulin stimulates androgen accumulation in incubations of ovarian stroma obtained from women with hyperandrogenism. J Clin Endocrinol Metab 1986; 62: 904-10.

16. Dunkel L, Sorva R, Voutilainen R. Low levels of sex hormonebinding globulin in obese children. J Pediatr 1985; 107: 95-7.

17. Nermen SA, Fattah A, Darwish YW. Is there any role for insulin resitence in non-obese patients with idiopathic hirsutism. Br J Dermatol 2009; 160: 1011-5.

18. Guzel Al, Kuyumcuoglu U, Celic Y. Factors affecting the degree of hirsutism in patients with polycystic ovary syndrome. Arch Gynecol Obstet 2012; 285: 767-70.

19. Unluhizarci K, Colak R, Sahin Y, et al. The prevalence of glucose intolerance in women with polycystic ovary syndrome. Turk J Endocrinol Metabol 2000; 4: 135-7.

20. Ehrmann DA, Barnes RB, Rosenfield RL, et al. Prevalence of impaired glucose tolerance and diabetes in women with polycystic ovary syndrome. Diabetes Care 1999; 22: 141-6.

21. Saxena P, Prakash A, Nigam A, Mishra A. Polycystic ovary syndrome: is obesity a sine qua non? A clinical, hormonal, and metabolic assessment in relation to body mass index. Indian J Endocrinol Metab 2012; 16: 996-9. 